\title{
Graphene-manganese oxide hybrid porous material and its application in carbon dioxide adsorption
}

\author{
ZHOU Ding ${ }^{1,2}$, LIU Qing ${ }^{1}$, CHENG QianYi ${ }^{1}$, ZHAO YanChao ${ }^{1}$, CUI Yi $^{1}$, WANG Tao $^{1} \&$ \\ HAN BaoHang ${ }^{1,2 *}$
}

${ }^{1}$ National Center for Nanoscience and Technology, Beijing 100190, China;

${ }^{2}$ State Key Laboratory of Transducer Technology, Chinese Academy of Sciences, Shanghai 200050, China

Received December 21, 2011; accepted February 1, 2012; published online May 14, 2012

\begin{abstract}
Graphene- $\mathrm{Mn}_{3} \mathrm{O}_{4}(\mathrm{GMNO})$ hybrid porous material is prepared by a hydrothermal method and its performance in carbon dioxide adsorption is investigated. In the synthesis of the GMNO materials, $\mathrm{MnO}(\mathrm{OH})_{2}$ colloid obtained by the hydrolysis of $\mathrm{Mn}^{2+}$ in basic solution was using as the precursor of the $\mathrm{Mn}_{3} \mathrm{O}_{4}$. After a hydrothermal reaction of the mixture of graphene oxide (GO) and $\mathrm{MnO}(\mathrm{OH})_{2}$, GO was reduced into graphene and the $\mathrm{MnO}(\mathrm{OH})_{2}$ was transformed into $\mathrm{Mn}_{3} \mathrm{O}_{4}$ with enhanced crystallization. X-ray diffraction, thermal gravimetric analysis, transmission electron microscopy, infrared spectra and Raman spectroscopy were taken to characterize the hybrid material. The porosity and the carbon dioxide adsorption ability are measured by gas sorption analysis, in which the as-prepared GMNO hybrid materials exhibit a specific surface area ranging from 140 to $680 \mathrm{~m}^{2} \mathrm{~g}^{-1}$ and a maximum carbon dioxide capacity of about $11 \mathrm{wt} \%$.
\end{abstract}

graphene, manganese oxide, porous material, carbon dioxide adsorption

Citation: Zhou D, Liu Q, Cheng Q Y, et al. Graphene-manganese oxide hybrid porous material and its application in carbon dioxide adsorption. Chin Sci Bull, 2012, 57: 3059-3064, doi: 10.1007/s11434-012-5158-3

The greenhouse gas, carbon dioxide, is the leading contributor of the global warming and climate change [1]. In the purpose of sustainability, scientists are devoting to find ways to control the carbon dioxide emission and separate/adsorb the greenhouse gas. For the latter one, there are four main approaches: cryogenic distillation, membrane purification, absorption with liquids [2], and adsorption using solids [3,4]. Using solid adsorbent is widely considered, such as zeolites [5,6], activated carbons [7,8], metal oxides $[9,10]$, and supported amines [11].

Considering the acidic nature of carbon dioxide, metal oxides which offer various basic sites are investigated widely as adsorbent. Many kinds of metal oxides display well in the performance of carbon dioxide adsorption, such as calcium oxide [9] and magnesium oxide [10]. Besides the basic sites contained in the solid adsorbent, the surface area is also an important factor. Porous metal oxide materials are

\footnotetext{
*Corresponding author (email: hanbh@nanoctr.cn)
}

synthesized and show high carbon dioxide uptake volume [12]. Meanwhile, metal oxide nanoparticles loading on or incorporating in the supporting material also show a significant increase in the surface area and gas adsorption ability [13].

In recent years, various kinds of graphene-inorganic hybrid materials are fabricated owing to the superior properties of graphene, i.e., the large theoretical specific surface area (about $2600 \mathrm{~m}^{2} \mathrm{~g}^{-1}$ ) and superior electronic and thermal properties [14,15]. Inorganic nanoparticles, i.e., metal [16] and metal oxides [17] have been successfully incorporated between graphene sheets, such materials have been investigated in a wide variety of applications in the fields of catalysis [18], gas sorption [13], and electrode materials [19]. Meanwhile, nanoparticles incorporated between graphene sheets effectively prevent the aggregation between graphene sheets in the hybrid system of the graphenenanoparticle composites [20,21], and the high porosity would increase their performance as an adsorbent and in 
other applications.

Manganese oxide $\left(\mathrm{MnO}_{x}\right)$ is a kind of low-cost and environmentally benign metal oxides with a high electrochemical activity and an environmental compatibility [22]. Graphene-manganese oxide hybrid materials are widely studied as electrode material in supercapacitor and lithium ion battery [23-25]. The hybrid materials show an enhanced performance compared to each component. However, the fabrication of graphene-manganese oxide porous material with a high surface area and the investigation of its gas sorption have not been reported.

Herein, we present a hydrothermal method of fabricating porous graphene- $\mathrm{Mn}_{3} \mathrm{O}_{4}(\mathrm{GMNO})$ material. In a hydrothermal reaction of the aqueous dispersion of $\mathrm{MnO}(\mathrm{OH})_{2}$ and $\mathrm{GO}$, the synthesis of $\mathrm{Mn}_{3} \mathrm{O}_{4}$ and the reduction of GO could proceed simultaneously. Owing to the driving force of chemisorption interaction, the $\mathrm{Mn}_{3} \mathrm{O}_{4}$ nanoparticles and graphene obtained in-situ assembled into three-dimensional structure with a high porosity. The gas sorption abilities of the as-prepared GMNO samples are different depending on the content of the $\mathrm{Mn}_{3} \mathrm{O}_{4}$ contained in the hybrid material. The largest surface area value of GMNO is about 680 $\mathrm{m}^{2} \mathrm{~g}^{-1}$ and the maximum carbon dioxide capacity could reach up to $11 \mathrm{wt} \%$.

\section{Experimental}

\subsection{Materials}

Natural flake graphite with an average particle diameter of $20 \mu \mathrm{m}$ (99 wt\% purity) was obtained from Yingshida graphite Co. Ltd., Qingdao, China. Sulfuric acid (98 wt\%), hydrogen peroxide (30 wt \%), sodium nitrate, manganese (II) acetate hydrate $\left(\mathrm{Mn}(\mathrm{Ac})_{2} \cdot 4 \mathrm{H}_{2} \mathrm{O}\right)$ and ethanol were purchased from Beijing chemical works, China. All these reagents were of reagent grade and used without further purification. Ultra-pure water $(18.2 \mathrm{M} \Omega \mathrm{cm})$ was obtained by the Millipore-ELIX water purification system.

\subsection{Preparation of $\mathrm{MnO}(\mathrm{OH})_{2}$ nanoparticles}

Aqueous $\mathrm{NaOH}$ solution $\left(0.1 \mathrm{~mol} \mathrm{~L}^{-1}\right)$ was added into aqueous $\mathrm{Mn}\left(\mathrm{CH}_{3} \mathrm{COO}\right)_{2}$ solution $\left(5 \mathrm{mg} \mathrm{mL}^{-1}\right)$ dropwisely until the $\mathrm{pH}$ value was about 12 . The transparent solution turned into yellow brown colloid without the appearance of a precipitate.

\subsection{Preparation of graphene- $\mathrm{Mn}_{3} \mathrm{O}_{4}$ hybrid porous materials}

Aqueous GO dispersion was prepared by chemical exfoliation of the natural flake graphite by a modified Hummers' method [26,27]. Aqueous GO dispersion was sonicated for 30 min prior to use. The colloidal dispersion of $\mathrm{MnO}(\mathrm{OH})_{2}$ was added into the $\mathrm{GO}$ dispersion $\left(1 \mathrm{mg} \mathrm{mL} \mathrm{m}^{-1}, 20 \mathrm{~mL}\right)$, and the mixture was diluted to $30 \mathrm{~mL}$ with ultra-pure water. After stirred for $6 \mathrm{~h}$, the mixture was transferred into a Teflon-lined stainless-steel autoclave (capacity: $50 \mathrm{~mL}$ ), and then heated to $180^{\circ} \mathrm{C}$ and maintained for $12 \mathrm{~h}$. After cooled down to room temperature, a cylinder-shaped black solid was obtained. The black product was collected by filtration and washed with ethanol trice, and dried at $60^{\circ} \mathrm{C}$ for $12 \mathrm{~h}$. The products are named as GMNO-1, GMNO-2, GMNO-3, GMNO-4, and GMNO-5 with different weight ratio of $\mathrm{Mn}(\mathrm{Ac})_{2} \cdot 4 \mathrm{H}_{2} \mathrm{O}$ to $\mathrm{GO}(8: 1,4: 1,1: 1,1: 4$, and $1: 8)$, respectively.

$\mathrm{Mn}_{3} \mathrm{O}_{4}$ and hydrothermal reduced graphene (HTG) were prepared as control samples by hydrothermal reaction of $\mathrm{MnO}(\mathrm{OH})_{2}$ or $\mathrm{GO}$ with the same condition as mentioned above.

\subsection{Instrumental characterization}

Nitrogen sorption and carbon dioxide sorption isotherms were obtained with a Micromeritics TriStarII3020 Surface Area and Porosity Analyze. The samples were degassed overnight at $150^{\circ} \mathrm{C}$. Nitrogen sorption analysis was measured at $77 \mathrm{~K}$, and the obtained nitrogen adsorptiondesorption isotherms were evaluated to give the pore parameters, including Brunauer-Emmett-Teller (BET) specific surface area, pore size, and pore volume. The carbon dioxide adsorption isotherms of the samples were collected at $273 \mathrm{~K}$.

Transmission electron microscopy (TEM) observations were carried out using a Tecnai $\mathrm{G}^{2} 20$ S-TWIN microscope (FEI, USA) at an accelerating voltage of $200 \mathrm{kV}$. GMNO samples were dispersed in ethanol and the dispersions were dropped on a copper grid and dried in vacuum at $60^{\circ} \mathrm{C}$ over night. Scanning electron microscopy (SEM) observations were carried out using a Hitachi S-4800 microscope (Hitachi Ltd., Japan) at an accelerating voltage of $6.0 \mathrm{kV}$ and equipped with a Horiba energy dispersive X-ray spectrometer (EDXS). The accelerating voltage is $20.0 \mathrm{kV}$ when taking SEM mapping images. X-ray diffraction (XRD) patterns of the samples were measured from $5^{\circ}$ to $90^{\circ}$ by a Philips $X^{\prime}$ Pert PRO X-ray diffraction instrument. Thermal gravimetric analysis (TGA) was performed on a Pyris Diamond thermogravimetric/differential thermal analyzer (PerkinElmer Instruments Co. Ltd, USA) by heating the samples from 30 to $800^{\circ} \mathrm{C}$ at a speed of $5^{\circ} \mathrm{C} \mathrm{min}^{-1}$ in the atmosphere of air.

Infrared (IR) spectra were recorded in potassium bromide pellets using a Spectrum One Fourier transform infrared (FTIR) spectrometer (Perkin-Elmer Instruments Co. Ltd, USA). Raman spectra were recorded with a Renishaw inVia Raman spectrometer (Renishaw plc, UK). All samples were tested in powder form on silicon wafer without using any solvent. The laser excitation was provided by a regular model laser operating at $514 \mathrm{~nm}$. 


\section{Results and discussion}

GO was prepared by the same method as our previous reports [28-30], in which the single-layered structure of GO sheet was conformed by atomic force microscope and the $\mathrm{C} / \mathrm{O}$ atomic ratio of $\mathrm{GO}$ was measured as 2.2 by X-ray photoelectron spectroscopy [31-33]. GO is frequently used as a precursor of graphene in the fabrication of graphene-based porous materials $[13,15]$. As reported in our previous studies, most of the oxygen-containing groups on GO sheets can be removed in a solvo-/hydro-thermal reaction [32]. In our preparation of GMNO materials, aqueous $\mathrm{NaOH}$ solution was added into aqueous $\mathrm{Mn}\left(\mathrm{CH}_{3} \mathrm{COO}\right)_{2}$ to prepare $\mathrm{MnO}(\mathrm{OH})_{2}$. The as-prepared $\mathrm{MnO}(\mathrm{OH})_{2}$ colloid was mixed with GO dispersion and the mixture was loaded into a Teflon-lined stainless-steel autoclave. After the hydrothermal reaction, $\mathrm{GO}$ was reduced into graphene and $\mathrm{MnO}(\mathrm{OH})_{2}$ transformed into $\mathrm{Mn}_{3} \mathrm{O}_{4}$. Owing to the chemisorption interaction between the two species, graphene sheets and $\mathrm{Mn}_{3} \mathrm{O}_{4}$ nanoparticles assembled together. Graphene sheets could also be considered as the substrate for the growth of $\mathrm{Mn}_{3} \mathrm{O}_{4}$ nanoparticles, therefore, the $\mathrm{Mn}_{3} \mathrm{O}_{4}$ nanoparticles do not tend to aggregate together and show better dispersibility in GMNO samples than in $\mathrm{Mn}_{3} \mathrm{O}_{4}$ sample. In the TEM and SEM images (Figure 1(a) and (d)) of the GMNO-3 sample, cubic nanoparticles with a size of about $20 \mathrm{~nm}$ are well dispersed on the graphene sheets. However, the particles in $\mathrm{Mn}_{3} \mathrm{O}_{4}$ sample (Figure 1(c)) and the graphene sheets in HTG sample (Figure 1(b)) show strong aggregation. Meanwhile, owing to the space between graphene sheets are limited, the size growth of $\mathrm{Mn}_{3} \mathrm{O}_{4}$ nanoparticles becomes more difficult with the existence of graphene, therefore, and the particle sizes of $\mathrm{Mn}_{3} \mathrm{O}_{4}$ nanoparticles are smaller in GMNO-3 than in $\mathrm{Mn}_{3} \mathrm{O}_{4}$ sample $(50 \mathrm{~nm})$. The carbon and manganese elements mapping images of GMNO-3 show that the different elements are dispersed uniformly in the hybrid material (Figure 2).

Figure 3 shows the XRD patterns of the hybrid materials, $\mathrm{MnO}(\mathrm{OH})_{2}$ and $\mathrm{Mn}_{3} \mathrm{O}_{4}$. $\mathrm{MnO}(\mathrm{OH})_{2}$ showed low-crystalline structure, and was transformed into $\mathrm{Mn}_{3} \mathrm{O}_{4}$ with increased crystalline after hydrothermal process. The XRD peaks of
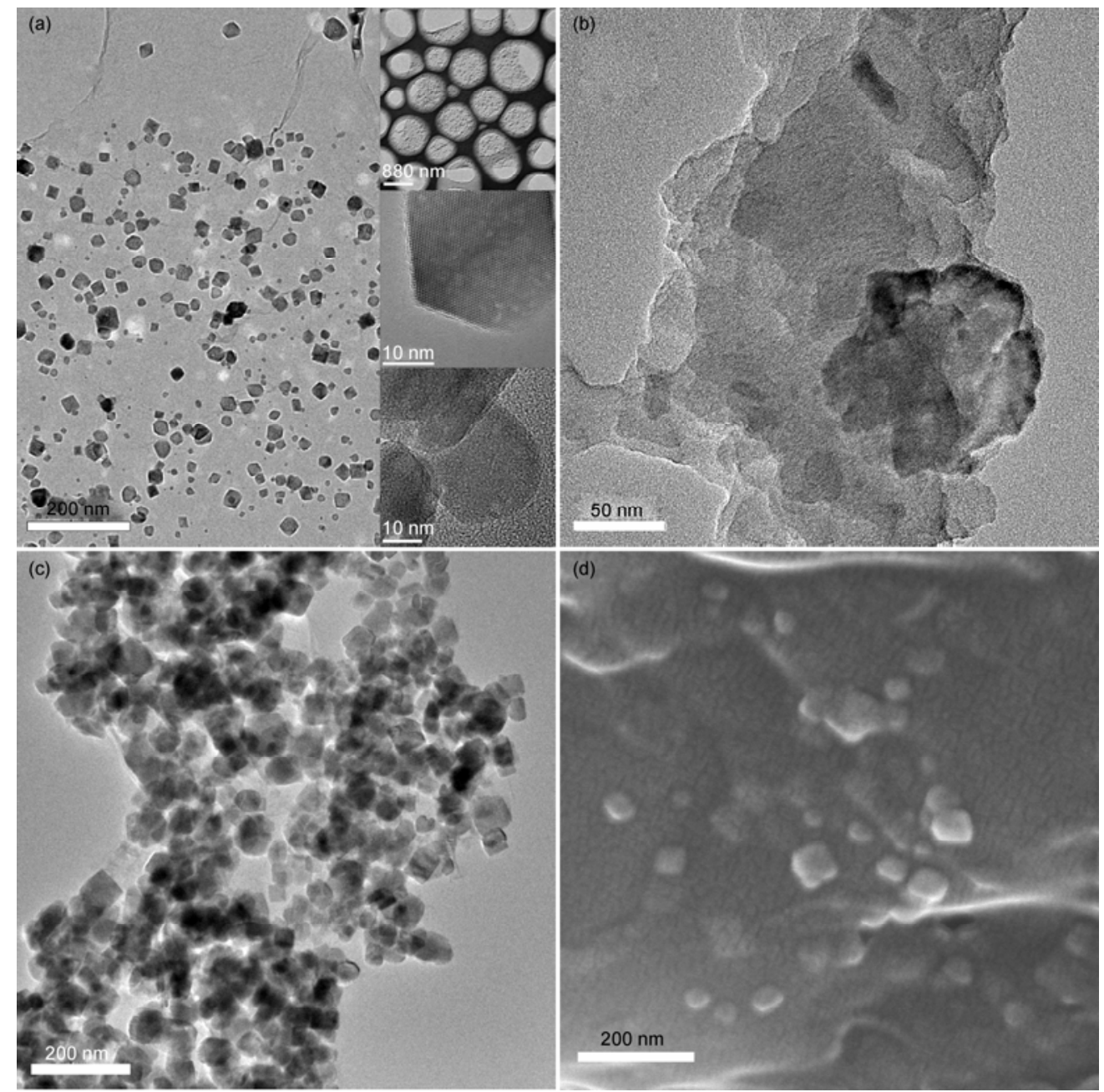

Figure 1 TEM images of GMNO-3 (a), HTG (b), and $\mathrm{Mn}_{3} \mathrm{O}_{4}$ (c), and SEM image of GMNO-3 (d). 

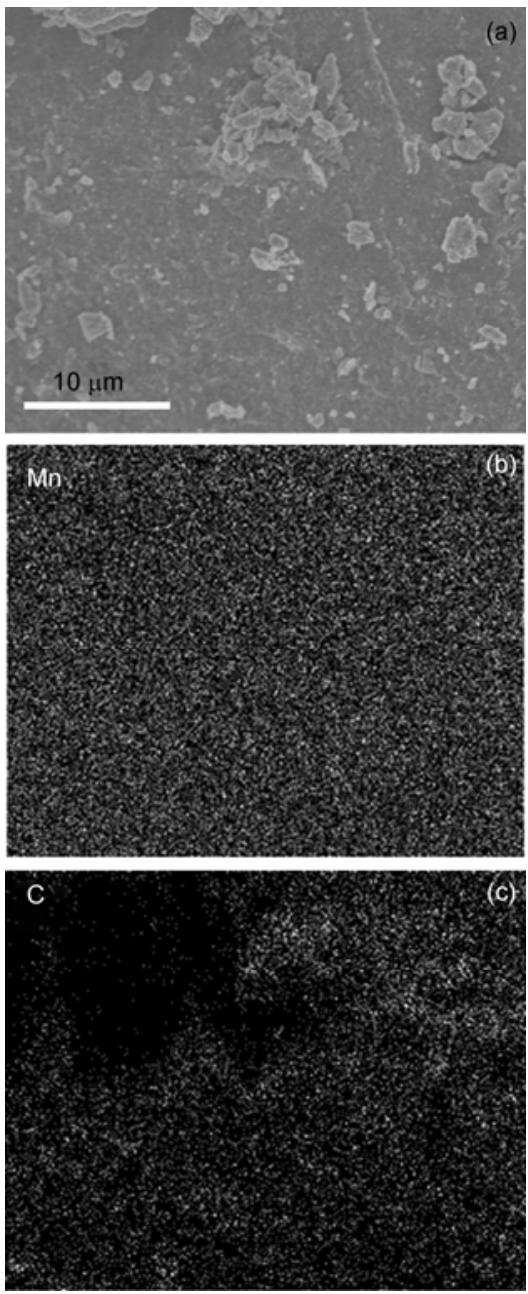

Figure 2 SEM image (a), Mn (b) and C (c) element mapping images of GMNO-3 (the white color in the element mapping images represent the dispersibility of the corresponding elements).

$\mathrm{Mn}_{3} \mathrm{O}_{4}$ and GMNO-3 are sharper, and the manganese oxide in $\mathrm{Mn}_{3} \mathrm{O}_{4}$ and GMNO are hausmannite. The crystal structure of the $\mathrm{Mn}_{3} \mathrm{O}_{4}$ growing on the graphene sheets is also revealed in the Figure 1(a). GMNO samples show a series of characteristic peaks at $17.9^{\circ}, 28.9^{\circ}, 32.3^{\circ}, 36.1^{\circ}$, and $59.8^{\circ}$, which can be assigned to the (101), (112), (103), (211), and (224) plane of the $\mathrm{Mn}_{3} \mathrm{O}_{4}$ (JCPDS No. 24-0734) [34].

Figure 4 shows the IR spectra for GO and GMNO-3. The absorption peak at $1730 \mathrm{~cm}^{-1}$ assigned to the carbonyl groups, which could be observed in the IR spectrum of GO but almost disappeared in the spectrum of GMNO-3. It is an evidence of the removal of the oxygen-containing groups on GO. GMNO-3 sample also shows two prominent absorption peaks at 506 and $610 \mathrm{~cm}^{-1}$ that can be assigned to the stretch vibration of the manganese and oxygen bond.

Figure 5 shows the Raman spectra of GO, HTG, GMNO-3, and $\mathrm{Mn}_{3} \mathrm{O}_{4}$. D- (ca. $1350 \mathrm{~cm}^{-1}$ ) and G- (ca. 1590 $\mathrm{cm}^{-1}$ ) bands are characteristic signal of carbon materials $[31,35]$. Compared with GO, HTG and GMNO show a slight increase in the $D / G$ intensity ratio, which might be

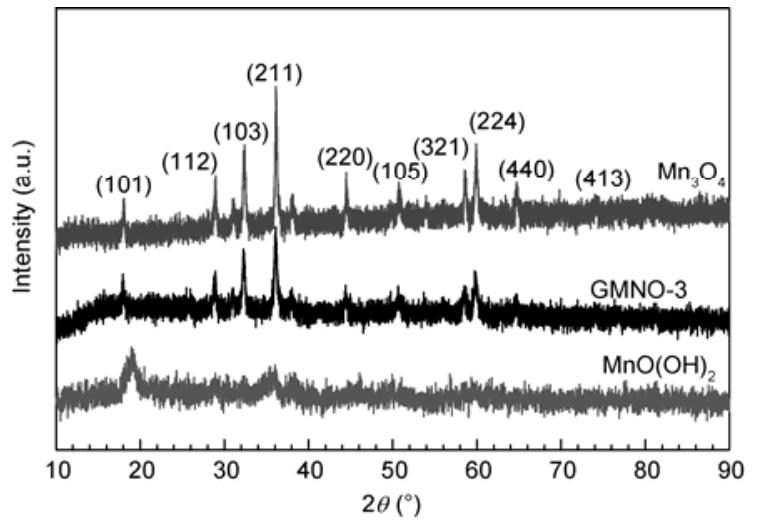

Figure 3 XRD patterns of $\mathrm{MnO}(\mathrm{OH})_{2}, \mathrm{Mn}_{3} \mathrm{O}_{4}$ and GMNO-3.

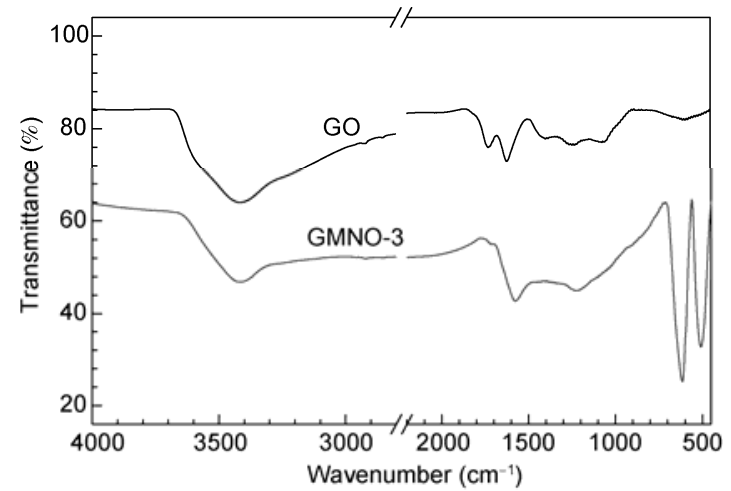

Figure 4 IR spectra of GO and GMNO-3 samples.

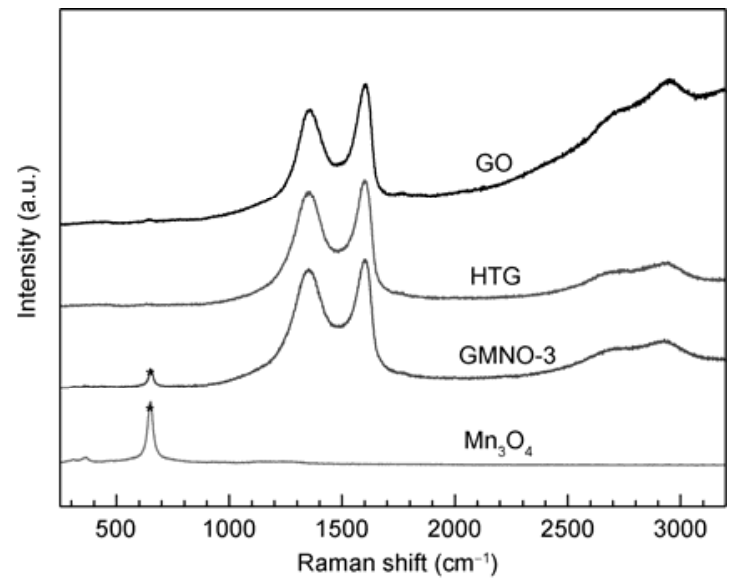

Figure 5 Raman spectra of GO, HTG, GMNO-3 and $\mathrm{Mn}_{3} \mathrm{O}_{4}$

because the "cutting effect" of hydrothermal treatment on GO [36]. Meanwhile, another peak at about $653 \mathrm{~cm}^{-1}$ is observed in the Raman spectrum of GMNO-3, which could be attributed to the $\mathrm{Mn}_{3} \mathrm{O}_{4}$ contained in the hybrid material.

Figure 6 shows the TGA results of GMNO samples. The skeleton of the graphene in the GMNO decomposed at a lower temperature $\left(300-400^{\circ} \mathrm{C}\right)$ compared to that of the HTG (about $550^{\circ} \mathrm{C}$ ), which might be caused by the reaction of skeleton carbon atoms and the manganese oxide 


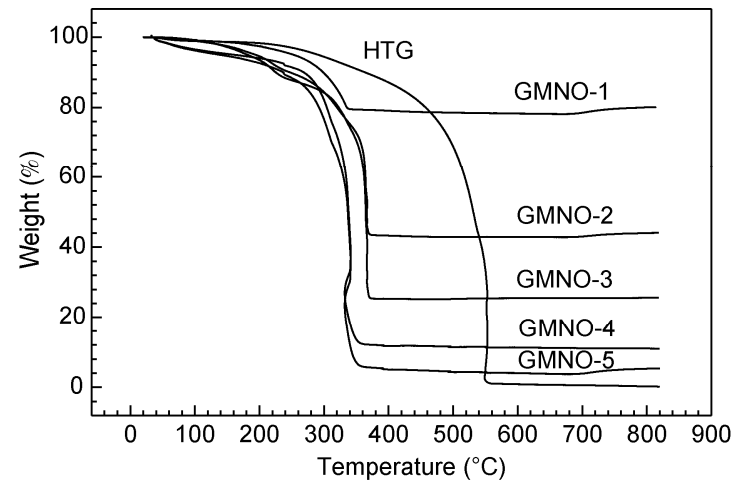

Figure 6 TGA results of GMNO samples.

nanoparticles. Meanwhile, the content of the $\mathrm{Mn}_{3} \mathrm{O}_{4}$ in the GMNO materials increase with the weight ratio of the manganese precursor to GO. The weight percentages of the $\mathrm{Mn}_{3} \mathrm{O}_{4}$ are $78 \%, 42.8 \%, 25.6 \%, 11.0 \%$, and $3.8 \%$ from GMNO-1 to GMNO-5, respectively.

GMNO samples show a small hysteresis loop at the relative pressure about $0.4-1.0$ (Figure 7), which is similar to the nitrogen sorption isotherms of the graphene-based inorganic porous material we reported before [13]. Owing to the different contents of the $\mathrm{Mn}_{3} \mathrm{O}_{4}$, the surface area values of the GMNO samples are varying from about 140 to 685 $\mathrm{m}^{2} \mathrm{~g}^{-1}$. The specific surface area of the GMNO samples decrease with the increase in the content of the $\mathrm{Mn}_{3} \mathrm{O}_{4}$ nanoparticles (Figure 7 and Table 1), which might be because the density of the $\mathrm{Mn}_{3} \mathrm{O}_{4}$ nanoparticles are larger than carbon materials.

The carbon dioxide capacities are list in Table 1 , and Figure 8 shows the comparison of the HTG, $\mathrm{Mn}_{3} \mathrm{O}_{4}$ and GMNO samples. $\mathrm{Mn}_{3} \mathrm{O}_{4}$ shows the lowest carbon dioxide adsorption capacity, and the value of HTG is about $7.7 \mathrm{wt} \%$ which is comparable to the carbon material previously reported $[1,3,4]$. The carbon dioxide adsorption capacities of the GMNO samples show a maximum value of about $11.4 \mathrm{wt} \%$ at GMNO-4, which is larger than HTG and $\mathrm{Mn}_{3} \mathrm{O}_{4}$. As observed in Figure 8(a), the carbon dioxide adsorption isotherms of HTG and $\mathrm{Mn}_{3} \mathrm{O}_{4}$ are slightly different, which might be owing to their different adsorption mechanisms. There are two main factors affect the carbon dioxide adsorption capacity for the GMNO samples, the surface area and the basic sites. HTG exhibits a similar carbon dioxide adsorption isotherm to other carbon materials and its

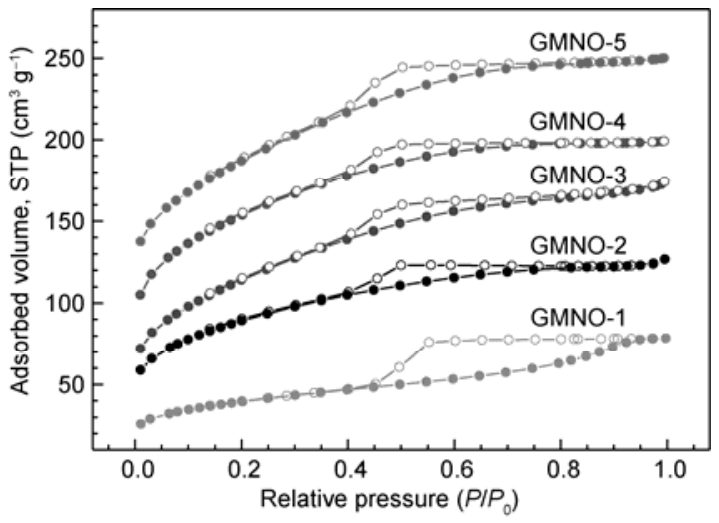

Figure 7 Nitrogen sorption isotherms of GMNO samples.
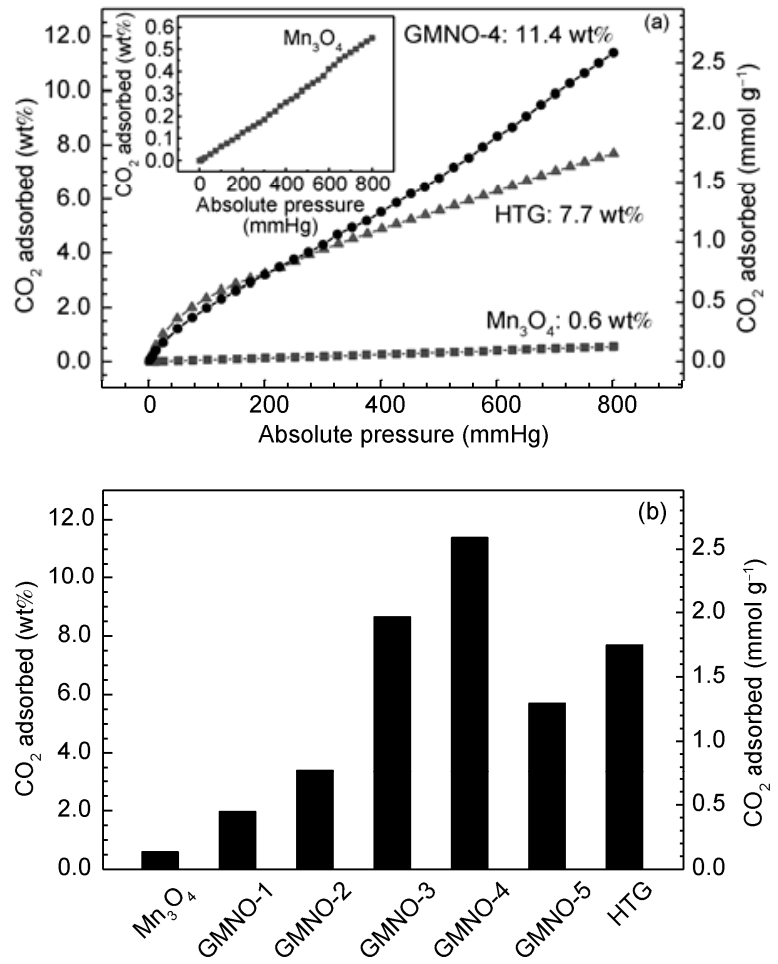

Figure 8 Carbon dioxide adsorption isotherms (a), and capacity comparison (b) of $\mathrm{HTG}, \mathrm{Mn}_{3} \mathrm{O}_{4}$ and GMNO samples. $1 \mathrm{mmHg}=1.33 \times 10^{2} \mathrm{~Pa}$.

carbon dioxide adsorption capacity is mainly depended on its surface area [1,4]. Whereas, the specific surface area of the $\mathrm{Mn}_{3} \mathrm{O}_{4}$ sample is low and the carbon dioxide adsorption

Table 1 Porosity parameters measured by nitrogen sorption and $\mathrm{CO}_{2}$ adsorption capacities of the samples

\begin{tabular}{|c|c|c|c|c|c|}
\hline & Weight ratio $\left(\mathrm{Mn}(\mathrm{Ac})_{2} \cdot 4 \mathrm{H}_{2} \mathrm{O}: \mathrm{GO}\right)$ & $S_{\text {BET }}\left(\mathrm{m}^{2} \mathrm{~g}^{-1}\right)$ & Pore size $(\mathrm{nm})$ & Pore volume $\left(\mathrm{cm}^{3} \mathrm{~g}^{-1}\right)$ & $\mathrm{CO}_{2}$ uptake (wt $\left.\%\right)$ \\
\hline GMNO-1 & $8: 1$ & 140 & 4.9 & 0.12 & 2.0 \\
\hline GMNO-2 & $4: 1$ & 283 & 4.3 & 0.19 & 3.4 \\
\hline GMNO-3 & $1: 1$ & 410 & 4.3 & 0.26 & 8.7 \\
\hline GMNO-4 & $1: 4$ & 541 & 4.3 & 0.31 & 11.4 \\
\hline GMNO-5 & $1: 8$ & 685 & 4.3 & 0.48 & 5.7 \\
\hline HTG & - & 647 & - & - & 7.7 \\
\hline
\end{tabular}


capacity is mainly contributed by the basic sites contained in the sample, the carbon dioxide uptake amount linearly increases with the pressure (inset in Figure 8(a)). Therefore, GMNO-4 shows the largest carbon dioxide uptake owing to the two factors.

\section{Conclusion}

Graphene- $\mathrm{Mn}_{3} \mathrm{O}_{4}$ materials with high porosity were prepared through the hydrothermal reaction, in which the reduction of $\mathrm{GO}$ and the formation of $\mathrm{Mn}_{3} \mathrm{O}_{4}$ are processing simultaneously. The specific surface area values of the as-prepared GMNO samples are different depending on the content of the $\mathrm{Mn}_{3} \mathrm{O}_{4}$, and the GMNO samples have a carbon dioxide adsorption amount up to $11.4 \mathrm{wt} \%$, which is comparable with other carbon materials.

This work was supported by the National Natural Science Foundation of China (91023001) and the Knowledge Innovation Program of Chinese Academy of Sciences (KJCX2-YW-H21).

1 Choi S, Drese J H, Jones C W. Adsorbent materials for carbon dioxide capture from large anthropogenic point sources. ChemSusChem, 2009, 2: 796-854

2 Lewis $\mathrm{T}$, Faubel $\mathrm{M}$, Winter $\mathrm{B}$, et al. $\mathrm{CO}_{2}$ capture in amine-based aqueous solution: Role of the gas-solution interface. Angew Chem Int Ed, 2011, 50: 10178-10181

3 Yin S F, Maruyama J, Yamashita T, et al. Efficient fixation of carbon dioxide by hypervalent organobismuth oxide, hydroxide, and alkoxide. Angew Chem Int Ed, 2008, 47: 6590-6593

4 D'Alessandro D M, Smit B, Long J R. Carbon dioxide capture: Prospects for new materials. Angew Chem Int Ed, 2010, 49: 6058-6082

5 Walton K S, Abney M B, Douglas LeVan M. $\mathrm{CO}_{2}$ adsorption in Y and $\mathrm{X}$ zeolites modified by alkali metal cation exchange. Micropor Mesopor Mat, 2006, 91: 78-84

6 Zhang J, Singh R, Webley P A. Alkali and alkaline-earth cation exchanged chabazite zeolites for adsorption based $\mathrm{CO}_{2}$ capture. $\mathrm{Mi}$ croporous Mesoporous Mater, 2008, 111: 478-487

7 Przepiórski J, Skrodzewicz M, Morawski A W. High temperature ammonia treatment of activated carbon for enhancement of $\mathrm{CO}_{2}$ adsorption. Appl Surf Sci, 2004, 225: 235-242

8 Zhao L, Bacsik Z, Hedin N, et al. Carbon dioxide capture on amine-rich carbonaceous materials derived from glucose. ChemSusChem, 2010, 3: 840-845

9 Juan Carlos A. The maximum capture efficiency of $\mathrm{CO}_{2}$ using a carbonation/calcination cycle of $\mathrm{CaO} / \mathrm{CaCO}_{3}$. Chem Eng J, 2002, 90: 303-306

10 Gregg S J, Ramsay J D. Adsorption of carbon dioxide by magnesia studied by use of infrared and isotherm measurements. J Chem Soc A, 1970, 2784-2787

11 Liang Z, Fadhel B, Schneider C J, et al. Stepwise growth of melamine-based dendrimers into mesopores and their $\mathrm{CO}_{2}$ adsorption properties. Microporous Mesoporous Mater, 2008, 111: 536-543

12 Özkan G, Özçelik E. $\mathrm{CO}_{2}$ adsorption on porous $\mathrm{NiO}$ as a cathode material for molten carbonate fuel cells. J Power Sources, 2005, 140: 28-33

13 Zhou D, Han B H. Graphene-based nanoporous materials assembled by mediation of polyoxometalate nanoparticles. Adv Funct Mater, 2010, 20: 2717-2722

14 Novoselov K, Geim A, Morozov S, et al. Electric field effect in atomically thin carbon films. Science, 2004, 306: 666-669

15 Compton O, Nguyen S. Graphene oxide, highly reduced graphene oxide, and graphene: Versatile building blocks for carbon-based materials. Small, 2010, 6: 711-723

16 Si Y, Samulski E. Exfoliated graphene separated by platinum nanoparticles. Chem Mater, 2008, 20: 6792-6797

17 Williams $\mathrm{G}$, Seger $\mathrm{B}$, Kamat $\mathrm{P}$. $\mathrm{TiO}_{2}$-graphene nanocomposites. $\mathrm{UV}$-assisted photocatalytic reduction of graphene oxide. ACS Nano, 2008, 2: 1487-1491

18 Scheuermann G, Rumi L, Steurer P, et al. Palladium nanoparticles on graphite oxide and its functionalized graphene derivatives as highly active catalysts for the Suzuki-Miyaura coupling reaction. J Am Chem Soc, 2009, 131: 8262-8270

19 Paek S, Yoo E, Honma I. Enhanced cyclic performance and lithium storage capacity of $\mathrm{SnO}_{2}$ /graphene nanoporous electrodes with three-dimensionally delaminated flexible structure. Nano Lett, 2009, 9: 72-75

20 Zhu Y, Murali S, Cai W, et al. Graphene and graphene oxide: Synthesis, properties, and applications. Adv Mater, 2010, 22: 3906-3924

21 Wei D, Liu Y. Controllable synthesis of graphene and its applications. Adv Mater, 2010, 22: 3225-3241

22 Qian Y, Lu S, Gao F. Synthesis of manganese dioxide/reduced graphene oxide composites with excellent electrocatalytic activity toward reduction of oxygen. Mater Lett, 2011, 65: 56-58

23 Chen S, Zhu J W, Wu X D, et al. Graphene oxide- $\mathrm{MnO}_{2}$ nanocomposites for supercapacitors. ACS Nano, 2010, 4: 2822-2830

24 Huang $\mathrm{H}$, Wang $\mathrm{X}$. Graphene nanoplate- $\mathrm{MnO}_{2}$ composites for supercapacitors: A controllable oxidation approach. Nanoscale, 2011, 3: 3185-3191

25 Wang $\mathrm{H} \mathrm{L}$, Cui L F, Yang Y, et al. $\mathrm{Mn}_{3} \mathrm{O}_{4}$-graphene hybrid as a high-capacity anode material for lithium ion batteries. J Am Chem Soc, 2010, 132: 13978-13980

26 Hummers W, Offeman R. Preparation of graphitic oxide. J Am Chem Soc, 1958, 80: 1339

27 Zu S Z, Han B H. Aqueous dispersion of graphene sheets stabilized by pluronic copolymers: Formation of supramolecular hydrogel. J Phys Chem C, 2009, 113: 13651-13657

28 Cheng Q Y, Zhou D, Gao Y, et al. Supramolecular self-assembly induced graphene oxide-based hydrogels and organogels. Langmuir, 2012, 28: 3005-3010

29 Xu J J, Wang K, Zu S Z, et al. Hierarchical nanocomposites of polyaniline nanowire arrays on graphene oxide sheets with synergetic effect for energy storage. ACS Nano, 2010, 4: 5019-5026

30 Yao P P, Chen P L, Jiang L, et al. Electric current induced reduction of graphene oxide and its application as gap electrdes in organic photoswitching devices. Adv Mater, 2010, 22: 5008-5012

31 Gao Y, Liu L Q, Zu S Z, et al. The Effect of interlayer adhesion on the mechanical behaviors of macroscopic graphene oxide papers. ACS Nano, 2011, 5: 2134-2141

32 Zhou D, Cheng Q Y, Han B H. Solvothermal synthesis of homogeneous graphene dispersion with high concentration. Carbon, 2011, 49: 3920-3927

33 Wu C, Cheng Q Y, Sun S Q, et al. Templated patterning of graphene oxide using self-assembled monolayers. Carbon, 2012, 50: 1083-1089

34 Cullity B D, Stock S R. Elements of X-ray Diffraction. 3rd ed. New Jersey: Prentice-Hall, 2001

35 Zhang D D, Zu S Z, Han B H. Inorganic-organic hybrid porous materials based on graphite oxide sheets. Carbon, 2009, 47: 2993-3000

36 Pan D, Zhang J, Li Z, et al. Hydrothermal route for cutting graphene sheets into blue luminescent graphene quantum dots. Adv Mater, 2010, 22: 734-738

Open Access This article is distributed under the terms of the Creative Commons Attribution License which permits any use, distribution, and reproduction in any medium, provided the original author(s) and source are credited. 